\title{
Association between Male Involvement in Birth Preparedness and Complication Readiness and women's use of institutional delivery in West Arsi Zone South Ethiopia: Cross-sectional study
}

Bikila Lencha Gemechu ( $\square$ lenibikimule@gmail.com )

Madda Walabu University https://orcid.org/0000-0003-0840-9460

Kassahun Ketema

Madda Walabu University

Girma Beresa

Madda Walabu University

Bonso Ami

Madda Walabu University

Aman Urgessa

Madda Walabu University

\section{Research}

Keywords: ANC, BPCR, Male, women, institution, delivery, West Arsi, South Ethiopia

Posted Date: March 13th, 2020

DOI: https://doi.org/10.21203/rs.3.rs-17143/v1

License: (c) (i) This work is licensed under a Creative Commons Attribution 4.0 International License.

Read Full License 


\section{Abstract}

Background: In sub-Saharan Africa (SSA), pregnancy and childbirth continue to be viewed as solely a woman's issues. Increasing partner participation and encouraging joint decision making in maternal health care may provide an important strategy in reducing maternal mortality and morbidity.

Objective: To assess the level of male partner involvement in Birth Preparedness and Complication Readiness (BPCR) and its association with women's use of institutional delivery among mothers who had a child less than 12 months in West Arsi Zone, South Ethiopia

Methods: Institutional based cross-sectional study was conducted in West Arsi Zone South Ethiopia in 2019. Systematic random sampling technique was used to select the study subjects. Data was collected using interviewer administered structured questionnaire. Binary and multivariable logistic regression was applied for the analysis of each of the independent variables against the dependent variable. The association between male involvement in BPCR and women's use of institutional delivery was done. The results were reported using crude and adjusted odds ratio (OR) with their $95 \%$ confidence interval.

Results: More than half of male partners, 407 (54.3\%) accompanied their wife during ANC follow up at least ones for the last pregnancy. Slightly more than three fourth, 571 (76.1\%) of male partners involved in BPCR for the last pregnancy. Fife hundred fifty-four (73.9\%) of the mothers gave birth in the health institution for the most recent child. Male involvement in BPCR $(\mathrm{aOR}=18.7,95 \% \mathrm{Cl}(11.1-31.6)$, joint decision making about place of delivery $(\mathrm{aOR}=3.2,95 \% \mathrm{Cl}: 1.76-5.7)$, urban residence $(\mathrm{aOR}=2.2,95 \%$ Cl: 1.32 - 3.7) and having two or less under-five children (aOR, 95\% Cl: $2.7(1.4-5.3)$ were associated with women's use of institutional delivery.

Conclusion: More than three fourth of male partners involved BPCR. Male involvement in BPCR, joint decision making about place of delivery, urban residence and having $\leq 2$ under-five children were associated with women's use of institutional delivery. Designing and implementing health education on the role of male partner in maternal health care is mandatory. Empowering rural mothers to use health institutions for delivery and birth spacing may improve the magnitude of institutional delivery.

\section{Plain English Summary}

Male involvement in maternal health care is a new approach, which is not well addressed in developing countries including Ethiopia. In Ethiopia, to improve the health of mothers at all levels of service starting from preconception to postpartum care, it is mandatory to participate male partners in order to get fruitful results. In the current study, we tried to identify the relationship between male involvement in birth preparedness plan and readiness for any anticipated complication with women's use of institutional delivery.

The current study showed that the level of male partner involvement in ANC and BPCR is encouraging. Accordingly, $54.3 \%$ male partners came to clinic with their wife during ANC follow up. Overall, $76.1 \%$ ) of 
male partners involved BPCR. Strong relationship was found between male involvement in BPCR and women use of institutional delivery. Joint decision making among the spouses also increased institutional delivery. In contrary, when women made decision alone, the odds of delivering in the health facility was reduced by $80 \%$. Additionally, rural residence and having more number of children also decreased institutional delivery. Thus, designing and implementing health education on the role of male partner in maternal health care is mandatory. Empowering rural mothers to use health institutions for delivery and birth spacing may improve the magnitude of institutional delivery.

\section{Background}

World health organization (WHO) defines male involvement in maternal health care as male attending antenatal care visits, birth plans, postnatal care (PNC) visit and decision-making with their wives on maternal health services [1]. The importance of male involvement in overall reproductive health including maternal health was given due attention since the 1994 International conference on Population Development [2].

Globally, male attendance of skilled ANC and delivery care remains a big challenge of the effort to improve maternal health care [3]. Absence of support from the husband is one of the main reasons for many pregnant women in sub-Saharan Africa not to seek maternity services [4]. This indicates that the characteristics of the health delivery system are not the only factors affecting the women's choices in uptake of maternal health care [5].

In Ethiopia, the national coverage of key MHC services remains critically low, as only $32 \%$ pregnant women attend at least four or more ANC visits, $28 \%$ delivered by a skilled provider and $17 \%$ women receive PNC within the first two days after birth [6]. These figures clearly indicate that the potential for improving maternal health care through increasing utilisation of these key services has not been fully addressed and remains one of the key areas for research and subsequent intervention.

Although men made most decisions for sexual and reproductive issues, pregnancy, child birth and rearing of children were regarded as women's responsibilities [7]. The study from Bangladesh showed that husbands' involvement in maternal health is a key factor associated with women's utilization of skilled maternal health services during pregnancy, childbirth and postpartum [8].

Education status, husbands' accompaniment during ANC, knowledge of BPCR, knowledge of danger signs of pregnancy, number of children, number of birth preparations, household wealth index, place of residence, travel time from home to nearest health facility, decision maker on place of delivery and frequency of ANC visit were associated with place of delivery [9- 14]. However, the association between male involvement in BPCR and women's use of institutional delivery was not well addressed in our setting.

The critical role that male partners play in women's reproductive health has been recognized for several years, more attention needs to be focused on involving men in maternal health interventions [15]. To our 
knowledge, there is no study that assessed the male involvement in BPCR and its association with women's use of institutional delivery in the study area despite the fact that their economic dominance and decision-making power remained high in our society. Thus, the study aimed to assess the association of male involvement in BPCR and women's use of institutional delivery among mothers who have children less than 12 months in West Arsi Zone South Ethiopia.

\section{Methods}

\section{Study setting and population}

Institutional based cross-sectional study was conducted in Public Hospitals and health centers of West Arsi Zone. West Arsi is one of the zones in Oromia Regional State with total population of about $2,507,643$. Shashemene town is the capital of the zone and located at $250 \mathrm{~km}$ to the South from Addis Ababa (West Arsi Zone health office statistics). The study was conducted in Public Hospitals and health centers of West Arsi Zone from March 1 to April 30, 2019. All women who have a child less than 12 months old in the Public Hospitals and health centers of West Arsi zone were our study population. Those caregivers other than the biological mother who brought the children for immunization were excluded and attempt was made to get biological mothers of the children.

\section{Sample size and sampling procedure}

Sample size was determined based on the single population proportion for cross sectional survey assuming $19.7 \%$ [16] of the proportion of male partners had accompanied their wife's to ANC, $49.2 \%$ of male partner involved in BPCR [17] and $26 \%$ of the institutional deliveries [6]. Finally, the minimum sample size of 804 was taken in order address all objectives

Simple random sampling was used to select five districts from the total districts of West Arsi Zone. Accordingly, shashemene, Arsi Negelle, Dodola, Adaba and Wondo Genet districts were randomly selected. The estimated number of mothers with a child of less than 12 months were obtained from zonal health office. Based on the obtained information, the sample size for each district was proportionally allocated. Then, the hospitals and health centers that are found in the randomly selected districts were listed along their average monthly client flow for immunization. Then, those public Hospitals and health centers with relatively large client load were purposively selected. Study subjects were again proportionally allocated for each selected institution.

The sampling interval was calculated by dividing the estimated mothers with a child of less than 12 months attending immunization in each institution during the study period for allocated sample size for the health institution. Finally, the study subjects were selected by systematic random sampling using every $k^{\text {th }}$ interval. First mother was selected by lottery method from institution and subsequent mothers were included randomly based on the interval.

Data collection instrument and procedures 
The data collection was carried out using structured and pre-tested questionnaire. The questionnaire was adapted after reviewing related literatures $[11,13,16]$. The questionnaire contained closed ended questions and it was developed in English language and translated into Afaan Oromo and back translated to English to ensure consistency and accuracy. It contained socio-demographic characteristics of the women and her partner, male involvement in ANC and BPCR. Information about the place of delivery, type of attendant and decision making power were also included.

\section{Study variables}

\section{The dependent variable is place of delivery (home versus institutional delivery). The main exposure variable was male involvement in ANC and BPCR. Other covariates were age, education, occupation of mother and husband, residence, religion, marital status, family size, number of under-five child, household assets, male accompany to ANC, HIV test, delivery, Decision making about place of delivery and Time of ANC Visit. Mothers with a child of less than 12 months attending immunization were used to minimize recall bias. The manuscript was prepared as per the STROBE guideline [25]}

\section{Data quality control}

To maintain the quality of the data structured and pre-tested questionnaire was used to collect data. Pretest was done in a health center which was out of study area and appropriate corrections were made to the questionnaire. Training was given to data collectors for one day on how to conduct the interview and content of the questionnaire. Data collectors were recruited by the investigators. Questionnaires was checked for completeness during data collection and incomplete ones were sent back to the data collectors for checkup under supervision. The supervisors checked the filled questionnaire daily.

\section{Operational definitions}

Male involvement in ANC: Whether a partner had accompanied his wife for at least one ANC visit during the most recent pregnancy resulting in a live birth.

Male involvement BPCR: A male will be considered as involved in BPCR if she (his wife) reported that; her husband involved in three of the following; saving money, identified health institution with 24-hour delivery service, arranging delivery by SBA, identified place of delivery, arranged transportation, identifying early sign of emergency, and arranged blood donor for the last delivery [18]. 
Male involvement during delivery: Husbands physically present at the birthplace during the time of delivery. Husbands could either be in the room with the woman while receiving the service or at another location within the premises where the service is received [8]

Decision-making: is whether the women can make decision, jointly with her partner or husband decides alone about the place of delivery and ANC attendance. For example; participants were asked "Who made the final decision of where to give birth?" The responses included "yourself", "your spouse," "jointly with your spouse," "other family member," "health professional," "friend," and "others"

Skilled Birth Attendance: A skilled birth attendant is a medically qualified provider with midwifery skills (Midwife, Nurse, Health Officer or doctor) who has been trained to proficiency in the skills necessary to manage normal deliveries and diagnose, manage, or refer obstetric complications.

Institutional delivery service utilization: a woman who gave birth in the health institution for the most recent delivery being assisted by skilled birth attendant

\section{Data processing and analysis}

Data was checked for completeness and entered in to Epi info version 7.0. It was exported to SPSS (statistical package for social sciences) version 21.0. Then cleaned, labeled and recoded in SPSS. Descriptive analysis was used to summarize the socio-demographic characteristics and the level of male involvement. Male involvement in ANC, BPCR and delivery care were assessed based on the women reports. Variables for which $p$-value is less than 0.25 by binary logistic regression analyses were entered into the model for subsequent multivariable logistic regression analyses. Involvement of the male in BPCR was considered as the primary exposure variable. Place of delivery was a dichotomous variable (home vs health institution) and considered as a dependent variable.

Principal component analysis (PCA) was used to compute wealth index. Seventeen household assets were used in computing PCA and all the assumptions (Correlation, KMO, Bartlett'es test of spherecity, MSA (measure of sampling adequacy), eigen value) were checked. Wealth index was divided into three categories as lowest, medium and highest. Multiple logistic regression model was done to identify the associations between husbands' involvement in BPCR and women's utilization of institutional delivery after controlling for other covariates. Stepwise forward logistic regression method was used for selection of variables in the model. Multi-collinearity was checked using standard error. Strength of the association was done using odds ratio (OR) with $95 \%$ confidence intervals $(95 \% \mathrm{Cl})$ at $\mathrm{p}$ value less than 0.05 .

\section{Results}

\section{Sociodemographic characteristics}

Seven hundred fifty women participated in the study with a response rate of $93.3 \%$. Mean age in years was $25.6(S D= \pm .18)$ for women and $31.9(S D= \pm .25)$ for their partners. Two hundred seventy women 
(35\%) completed secondary and above level of education. Most of the women 471 (62. 8\%) were housewives and 146 (19.5\%) were employed. Around two third of women 483 (64.4\%) were living in urban areas and the rest 267 (35.6\%) reside in rural area. Six hundred sixty-two (88.3\%) of the mothers had two or less under five-year-old children. Concerning educational status of the husband, more than half 391 (52.1\%) completed secondary and above level of education. Majority of husbands 325 (43.3\%) were farmers while $193(25.7 \%)$ of them were employed (Table 1 ).

\section{Maternal health care service utilization in West Arsi Zone, 2019.}

Majority 719 (95.9\%) of the mothers received antenatal care service at least once from health care providers. Mean time of first ANC follow up was $4.5(S D= \pm 1.4)$ months. Of the 719 mothers who attended ANC at least once, decision of ANC attendance was made jointly (i.e. both husband and wife) in 601 (83.5\%). Slightly less than three fourth 554 (73.9\%) of the mothers gave birth in the health institution for the most recent child. One in four $196(26.1 \%)$ mothers were still giving birth at home. Four hundred and fifty-six (60.8\%) mothers reported that decision about place of delivery was made jointly with husband (Fig. 1).

\section{Male involvement in Maternal health care in West Arsi Zone, 2019.}

More than half of male partners 407 (54.3\%), accompanied their wife during ANC follow up at least ones during the last pregnancy. Among 554 mothers who gave birth in the health institution for the most recent child, 509 (91.8\%) of them were accompanied by their male partners.

Seven questions with dichotomous responses were used to assess the level of male involvement in birth preparedness and complication readiness. Six hundred seven (80.9\%), 551 (73.5\%), 545 (72.7\%), 542 (72.3\%), 536 (71.5\%), 402 (53.6\%), and 133 (17.7\%) of male partners involved in saving money, identifying health institution with 24-hour delivery service, arranging delivery by SBA, identifying place of delivery, arranging transportation, identifying early sign of emergency, and arranged blood donor for the last delivery, respectively. Overall, $571(76.1 \%)$ of male partners involved in birth preparedness and complication readiness (BPCR) for the last pregnancy (Fig 2.).

\section{Factors associated with institutional delivery among mothers who had children less than 12 months in West Arsi Zone, 2019.}

Socio-demographic variables like age, educational status, occupation, religion, residence, family size, number of under-five children in the household and wealth index were found to be associated with institutional delivery at p-value less than 0.05 in the bi-variable logistic regression analysis (Table 3 ). 
Additionally, health care related variables like ANC attendance, male accompany to ANC, male involvement in BPCR and decision making power about place of delivery were associated with institutional delivery.

In the multivariable logistic regression, four variables remained statistically significantly associated with institutional delivery: male involvement in BPCR (adjusted odds ratio [aOR], 95\% confidence interval [CI]: 18.7 (11.1 - 31.6), decision making about place of delivery; women alone (aOR, 95\% Cl: .20 (.09 - .43)), husband and wife jointly (aOR, 95\% Cl: $3.2(1.76-5.7)$ ), having 2 or less under-five children (aOR, 95\% Cl: $2.7(1.4-5.3))$ and urban residence (aOR, 95\% Cl: $2.2(1.32-3.7))$.

Those mothers whose husbands involved in BPCR were 18.7 (95\% Cl: 11.1- 31.6) times more likely to deliver in the health institution compared to mothers whose husbands didn't involve in BPCR. When women made the final decision about place of delivery being alone, the odds of giving birth in the health facility was reduced by $80 \%$; AOR $=.20(95 \% \mathrm{Cl} .09-.43)$. On the other hand, joint decision making increased the odds of institutional delivery by $3.2(95 \% \mathrm{Cl}: 1.76-5.7)$ times compared to the others like health professionals, friend and or family member.

Those mothers who had two or less under-five children were 2.7 (95\% Cl: $1.4-5.3)$ times more likely to deliver in the health institutions compared to those who had three or more under-five children. Those mothers who were living in urban areas were $2.2(95 \% \mathrm{Cl}$ : 1.32 - 3.7) times more likely to deliver in the health institutions compared to those mothers who live in rural areas.

\section{Discussion}

In the current study, 571 (76.1\%) of male partners involved in BPCR for the last pregnancy. There is strong association between male involvement in BPCR and women use of institutional delivery. Other variables like joint decision making about place of delivery, urban residence and having two or less under-five children were also associated with women use of institutional delivery. The study suggested that woman's utilization of institutional delivery can be improved by involving their husbands in birth preparedness and complication readiness. Empowering couples to make joint decision making about place of delivery may also improve the level of institutional delivery.

In the current study, more than half of male partners 407 (54.3\%), accompanied their wife during ANC follow up at least ones for the last pregnancy. This was slightly higher compared to systematic review and meta-analysis conducted in SSA countries which reported that (45.7\%) of all men in the study population reported being present during one of his partner's antenatal check-ups [19]. The justification could be awareness created during the past five years. Our finding agrees to the prospective cohort study in Southern Nations Nationalities and Peoples of Ethiopia [10] and other studies in Uganda and Bangladesh $[8,15]$

Male involvement in BPCR was strongly associated with women use of institutional delivery. Those mothers whose husbands involved in BPCR were eighteen times more likely to deliver in the health 
institution compared to mothers whose husbands didn't involve in BPCR. This was similar to the crosssectional study which was conducted in Southeast Ethiopia [20]. If male partners involved starting from saving money and even up to arrangement of blood donor, the odds of their spouse to give birth in the health institution is high.

The current study identified that joint decision making among the spouse was associated with institutional delivery. This was similar to the study from Tanzania which reported that agreement of partners regarding the place of delivery is important factor in determining delivery in the health facility [12]. Similar finding was reported from the cross-sectional study which was conducted in remote area of Bale Zone [14].

When women made decision alone, the odds of delivering in the health facility was reduced by $80 \%$. The study from Tanzania also reported that, when women made the final decision alone; the odds of giving chance to birth assisted by SBAs was significantly reduced [12].

In the current study, place of residence was also associated with place of delivery. Those mothers who were living in urban areas were more likely to deliver in the health institutions compared to those mothers who were living in rural areas. This finding is in agreement with the successive national demographic and health survey findings of Ethiopia $(6,21]$. This finding also agrees with the other study conducted in Southeast Ethiopia and SNNP [10,14]. The study from Nepal also indicated that the odds of delivering in an institution was higher among urban women compared to women who lived in rural areas [22].

The number of under-five children was also another factor which was associated with women's use of institutional delivery. Those mothers who had two or less under-five children were more likely to deliver in the health institutions compared to those who had three or more under-five children. Similarly, the study from Tanzania has shown that those women who were delivering their first child were more likely to use health facility compared to their counterparts [9]. Similar findings were reported from studies conducted in Ethiopia [10,24]. They indicated that, as the number of births that a woman gave increases her usage of the maternal health care decreases

The prospective cohort study which was conducted in SNNP region identified strong association between male involvement in ANC and women use of skilled birth attendant [10]. Similar finding was reported from Uganda [23] Our study also identified similar association in bi-variable analysis. However, it didn't remain significant in the model after adjusting for other confounding variables.

\section{Limitations Of The Study}

Only womens were participated in the current study and the issue of social desirability bias can't be excluded. The current study is cross-sectional, and so the association between male involvement in BPCR and the womens use of institutional delivery cannot be determined without error. Large sample size was used which enabled us to estimate the difference precisely and generalize the finding to West Arsi Zone. The finding should be interpreted taking into consideration the limitations and remedies listed above. 


\section{Conclusions}

More than three fourth of male partners involved in BPCR for the last pregnancy. Male involvement in BPCR was strongly associated with women's use of institutional delivery. Other variables like: joint decision making about place of delivery; having 2 or less under-five children and urban residence were also associated with women's use of institutional delivery. Health care providers need to focus on information, education and communication (IEC) with emphasis to counselling on joint decision making about ANC follow up and place of delivery Program planners must give attention to rural women's since they are contributing vast majority of home delivery in our study setting. The policy makers must consider the role of male partners in promoting institutional deliveries and focus on addressing the bottlenecks. Generally, addressing all the identified variables has paramount importance to achieve sustainable development goal of reducing maternal mortality to less than 70 per 100000 live births by 2030 .

\section{Declarations}

\section{Ethical approval and consent to participate}

Ethical approval was obtained from Madda Walabu University Research Ethical Review Committee. Permission letter was obtained from zonal and district health offices. Permission was obtained from Hospital and health center managers to conduct the study. It was explained to the participants as the participation was voluntary; their response is confidential and they can withdraw from the study at any time without prior explanation. All respondents were informed about the objective of the study and verbal consent was obtained. All the information given by the respondents were used for research purposes only

\section{Consent for publication}

Not applicable

Availability of data and materials

\section{The datasets used during the current study are available in the manuscript and uploaded as supplementary material}

Competing interests

The authors declare that they have no competing interests.

Authors' contributions

BL : Conceptualization of the study, formulated the research question, designed data collection tool, conducted data analysis, write up and drafted the manuscript. 
$\mathrm{BL}, \mathrm{GB}, \mathrm{KK}, \mathrm{BA}, \mathrm{AU}$ : participated in formulation of the research question, design of the study, and carried out data analysis.

$\mathrm{KK}, \mathrm{GB}, \mathrm{BA}, \mathrm{AU}$ : participated in the supervision of data collection, data analysis, write up and reviewing the manuscript. . All authors read and approved the final version of the manuscript.

Funding: Not applicable

\section{Acknowledgements}

Our thanks go to those West Arsi Zone Health Office, Hospitals and health centers. We also thank our data collectors and supervisors for their commitment throughout the research work.

\section{Abbreviations}

ANC Ante Natal Care

BPCR Birth Preparedness and Complication Readiness

$\mathrm{Cl}$ Confidence Interval

ICPD International Conference on Population and Development

MHC Maternal Health Care

OR Odds Ratio

PCA Principal Component Analysis

PNC Post Natal Care

SPSS Statistical Package for Social Sciences

SSA Sub-Saharan Africa

WHO World Health Organization

\section{References}

1. World Health Organization 2007. Working with Individuals, Families and Communities to Improve Maternal and Newborn Health. Making Pregnancy Safer Initiative. Reproductive Health Research. Geneva, Switzerland.

2. United Nations 1995. Report of International conference on Populations and Developement Cairo, 513 September 1994. United Nations, New York: United Nations 
3. Tweheyo R, Konde-Lule J, Tumwesigye NM, Sekandi JN, Male partner attendance of skilled antenatal care in peri-urban Gulu district, Northern Uganda. BMC Pregnancy and Childbirth.10, 53 (2010). Doi: 10.1186/1471-2393-10-53

4. Gross et al. 2012, Timing of antenatal care for adolescent and adult pregnant women in southeastern Tanzania. BMC Pregnancy and Childbirth 12:16.

5. Baral YR, Lyons K, Skinner J, van Teijlingen ER 2010, Determinants of skilled birth attendants for delivery in Nepal

6. Central Statistical Agency (CSA) [Ethiopia] and ICF. (2016) Ethiopia Demographic and Health Survey 2016: Key Indicators Report. Addis Ababa, Ethiopia, and Rockville, Maryland, USA. CSA and ICF.

7. Kura S, Vince $\mathrm{J}$ \&Chivers CP, 2013 Male involvement in sexual and reproductive health in the Mendi district, Southern Highlands province of Papua New Guinea: a descriptive study. Reproductive Health $10: 46$.

8. Rahmanet alKnowledge and involvement of husbandsin maternal and newborn health in ruralBangladesh.BMC Pregnancy and Childbirth (2018) 18:247 https://doi.org/10.1186/s12884-0181882-2

9. Bishanga DR, Drake M, Kim Y-M,Mwanamsangu AH, Makuwani AM, Zoungrana J,et al. (2018) Factors associated with institutionaldelivery: Findings from a cross-sectional study inMara and Kagera regions in Tanzania. PLoS ONE13(12): e0209672. https://doi.org/10.1371/journal. pone.0209672

10. Teklesilasie and Deressa. Husbandsinvolvement in antenatal careand its association with womens utilization of skilled birth attendants in Sidama zone,Ethiopia: a prospective cohort study. BMC Pregnancy and Childbirth (2018) 18:315 https://doi.org/10.1186/s12884-018-1954-3

11. Nanjala M \& Wamalwa D. Determinants of Male Partner Involvement in Promoting Deliveries by Skilled Attendants in Busia, Kenya Global Journal of Health Science Vol. 4, No. 2; March 2012 doi:10.5539/gjhs.v4n2p60 URL: http://dx.doi.org/10.5539/gjhs.v4n2p60

12. Danforth, E. J., Kruk, M. E., Rockers, P. C., Mbaruku, G. \&Galea, S. 2009. Household Decision-making about delivery in Health Facilities: Evidence from Tanzania. J Health PopulNutr, 27.

13. Yargawa, J. \&Leonardi-Bee, J. 2015. Male involvement and maternal health outcomes: systematic review and meta-analysis. Journal of Epidemiology and Institutional Health, 69, 604-612.

14. Ayele GS, Melku AT and Belda SS.Utilization of skilled birth attendant at birthand associated factors among women whogave birth in the last 24 months precedingthe survey in Gura Dhamole Woreda, Balezone, southeast Ethiopia. BMC Public Health(2019) 19:1501https://doi.org/10.1186/s12889019-7818-6

15. Kakaire O, Kaye DK, Osinde MO, 2011 Male involvement in birth preparedness and complication readiness for emergency obstetric referrals in rural Uganda. Reprod Health, 8(12):1-7

16. Fekede A, Ayele G, Yadeta D. Male Partners Involvement in Maternal ANC Care: The View of Women Attending ANC in Harari public Health Institutions, Eastern Ethiopia. Science Journal of Public Health. Vol. 2, No. 3, 2014, pp. 182-188. doi: 10.11648/j.sjph.20140203. 
17. Bayissa, D. D., Bulto, A. G. \&Terfassa, G. T. 2016. Involvement of Male in Antenatal Care, Birth Preparedness and Complication Readinessand Associated Factors in Ambo Town, Ethiopia. Journal of Health, Medicine and Nursing 27, 1-10.

18. Kaso, M. \&Addisse, M. 2014. Birth preparedness and complication readiness in RobeWoreda, Arsi Zone, Oromia Region, Central Ethiopia: a cross-sectional study. Reproductive Health, , 11, 1-12.

19. Jennings L, MuziN, Cherewick M, Hindin M et al. 2014 Women's empowerment and male involvement in antenatal care: analyses of Demographic and Health Surveys (DHS) in selected African countries.BMC Pregnancy and Childbirth 14:297

20. Fikadu C. Male involvement in birth preparedness and complication readiness and its associated factors among married male in Dinsho district Bale Zone Oromia 2016, Master's thesis).

21. Central Statistical Agency [Ethiopia] and ICF International. 2012. Ethiopia Demographic and HealthSurvey 2011. Addis Ababa, Ethiopia and Calverton, Maryland, USA: Central Statistical Agency andICF International

22. Shahabuddin ASM, De Brouwere $V$, Adhikari $R$, etal. Determinants of institutional delivery among young married women in Nepal: Evidence from the Nepal Demographic and Health Survey, 2011. BMJ Open 2017;7:e012446. doi:10.1136/ bmjopen-2016-012446

23. Kabakyenga JK, O"stergren P-O, Turyakira E, Pettersson KO (2012) Influence of Birth Preparedness, Decision-Making on Location of Birth and Assistance by Skilled Birth Attendants among Women in South-Western Uganda. PLoS ONE 7(4): e35747 doi: 10.1371/journal.pone.0035747

24. Kifle et al., Maternal health care service seeking behaviors and associated factors among women in rural Haramaya District, Eastern Ethiopia: a triangulated community-based cross-sectional study Reproductive Health (2017) 14:6 DOI 10.1186/s12978-016-0270 5

25. von Elm E, Altman DG, Egger M, Pocock SJ, Gotzsche PC, Vandenbroucke JP. The Strengthening the Reporting of Observational Studies in Epidemiology (STROBE) Statement: guidelines for reporting observational studies.

\section{Tables}

\section{Table 1. Sociodemographic characteristics of the respondents and their partners, West Arsi Zone, 2019.}




\begin{tabular}{|c|c|c|}
\hline Variable & Frequency & Percent \\
\hline \multicolumn{3}{|l|}{ Age of mother } \\
\hline $15-24$ & 314 & 41.9 \\
\hline $25-34$ & 372 & 49.6 \\
\hline 35 and above & 64 & 8.5 \\
\hline \multicolumn{3}{|l|}{ Religion } \\
\hline Muslim & 536 & 71.5 \\
\hline Orthodox & 122 & 16.3 \\
\hline Protestant & 86 & 11.5 \\
\hline Others* & 6 & .8 \\
\hline \multicolumn{3}{|l|}{ Ethnicity } \\
\hline Oromo & 653 & 87.1 \\
\hline Amhara & 62 & 8.3 \\
\hline Others** & 35 & 4.7 \\
\hline \multicolumn{3}{|c|}{ Occupation of mother } \\
\hline Unemployed & 604 & 80.5 \\
\hline Employeed & 146 & 19.5 \\
\hline \multicolumn{3}{|c|}{ Educational status of mother } \\
\hline illiterate & 127 & 16.9 \\
\hline literate & 623 & 83.1 \\
\hline \multicolumn{3}{|c|}{ Age of husband } \\
\hline $18-29$ & 264 & 35.2 \\
\hline 30 and above & 486 & 64.8 \\
\hline \multicolumn{3}{|c|}{ Educational status of husband } \\
\hline illiterate & 59 & 7.9 \\
\hline literate & 691 & 92.1 \\
\hline
\end{tabular}

$*_{-} 7^{\text {th }}$ day Adventist, catholic **-Tigre, Wolaita, Gurage

Table 2. Factors associated with institutional delivery among mothers who had children less than 12 months in West Arsi Zone, 2019 
Health Home

inst.

\section{Age of mother}

\begin{tabular}{|c|c|c|c|}
\hline $5-24$ & 246 & 68 & $1.8(1.1 .-3.4)$ \\
\hline $25-34$ & 266 & 106 & $1.3(.7-2.3)$ \\
\hline 5 & 42 & 22 & Ref \\
\hline
\end{tabular}

above

\section{Education of mother}

\begin{tabular}{llll} 
Literate & 496 & 127 & $4.6(3.1-6.9)$ \\
\hline Illiterate & 58 & 69 & Ref
\end{tabular}

\section{Occupation of mother}

\begin{tabular}{lllll} 
Employed & 131 & 15 & $3.7(2.1-6.5)$ & Ref \\
\hline Unemployed & 423 & 181 & Ref & \\
\hline Residence & & & & $2.2(1.32-$ \\
Urban & 416 & 67 & $5.8(4.1-8.3)$ & $3.7)$ \\
\hline Rural & 138 & 129 & Ref & Ref
\end{tabular}

\section{Age of}

husband

\begin{tabular}{llll}
\hline $18-29$ & 211 & 53 & $1.6(1.2-2.4)$ \\
\hline$>=30$ & 343 & 143 & Ref
\end{tabular}

\section{Education partner}

$\begin{array}{llll}\text { Literate } & 526 & 165 & 3.5(2.1-6.1) \\ \text { Illiterate } & 28 & 31 & \text { Ref }\end{array}$

\section{Occupation of husband}

\begin{tabular}{lllll}
\hline Farmer & 188 & 137 & Ref & Ref \\
\hline Employer & 169 & 24 & $5.1(3.1-8.3)$ &
\end{tabular}

\begin{tabular}{llll}
\hline Merchant & 125 & 22 & $4.1(2.5-6.8)$ \\
\hline Others* & 72 & 13 & $4.0(2.1-7.6)$ \\
\hline
\end{tabular}

ANC Follow

up

\begin{tabular}{llll} 
Yes & 543 & 176 & $5.6(2.6-11.9)$ \\
\hline No & 11 & 20 & Ref
\end{tabular}

Male accompany to ANC

\begin{tabular}{lllll}
\hline Yes & 346 & 61 & $3.6(2.6-5.2)$ & - \\
\hline No & 208 & 135 & Ref & Ref
\end{tabular}


Male tested for HIV

\begin{tabular}{|c|c|c|c|c|}
\hline Yes & 311 & 37 & $5.5(3.7-8.1)$ & - \\
\hline No & 243 & 159 & Ref & Ref \\
\hline \multicolumn{5}{|c|}{ Male involvement in Birth Preparedness and Complication Readiness } \\
\hline Yes & 518 & 53 & $38.8(24.5-61.6)$ & $\begin{array}{l}18.7 \text { (11.1- } \\
31.6)\end{array}$ \\
\hline No & 36 & 143 & Ref & Ref \\
\hline \multicolumn{5}{|c|}{ Decision of place of delivery } \\
\hline Wife alone & 18 & 90 & $.09(.05-.17)$ & $\begin{array}{l}.20(.09- \\
.43)\end{array}$ \\
\hline $\begin{array}{l}\text { Husband } \\
\text { alone }\end{array}$ & 22 & 21 & $.48(.24-.96)$ & $\begin{array}{l}.41 \\
1.03)\end{array}$ \\
\hline Jointly & 416 & 40 & $4.7(2.95-7.7)$ & $\begin{array}{l}3.2(1.76 \\
-5.7)\end{array}$ \\
\hline Others** & 98 & 45 & Ref & Ref \\
\hline \multicolumn{5}{|c|}{ Wealth index of household } \\
\hline Rich & 209 & 21 & $9.5(5.7-15.8)$ & - \\
\hline Medium & 213 & 49 & $4.15(2.3-6.2)$ & - \\
\hline Poor & 132 & 126 & Ref & Ref \\
\hline \multicolumn{5}{|c|}{ Number of U5 } \\
\hline$<=2$ & 503 & 159 & $2.2(1.45-3.6)$ & $\begin{array}{l}2.7(1.4- \\
5.3)\end{array}$ \\
\hline$>=3$ & 51 & 37 & Ref & Ref \\
\hline \multicolumn{5}{|l|}{ Family size } \\
\hline$<=5$ & 429 & 93 & $3.8(2.69-5.4)$ & - \\
\hline$>5$ & 125 & 103 & Ref & Ref \\
\hline
\end{tabular}

*Driver, unemployed, student ** health professionals, friend, family member

Figures 


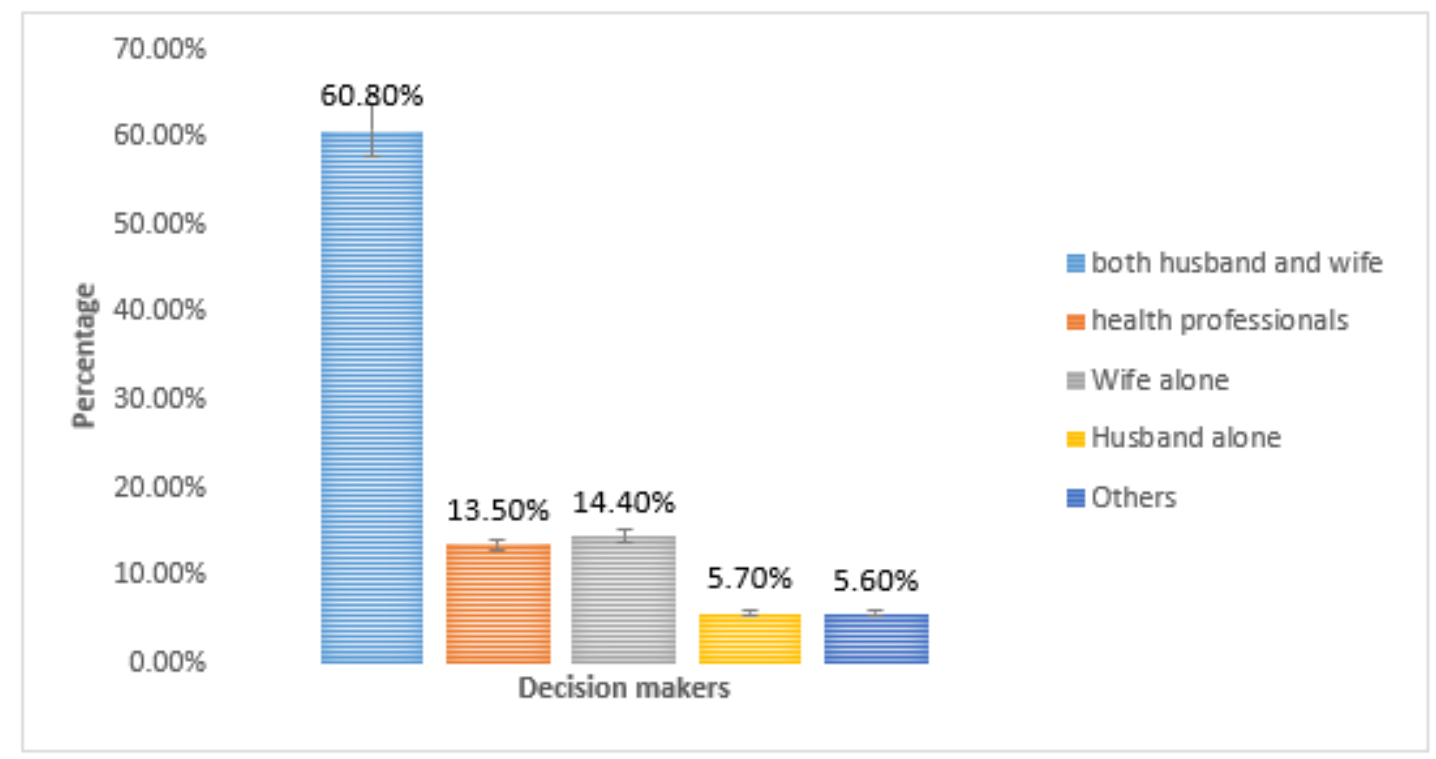

\section{Figure 1}

Decision makers about place of delivery among mothers who had children less than 12 months in West Arsi Zone, 2019

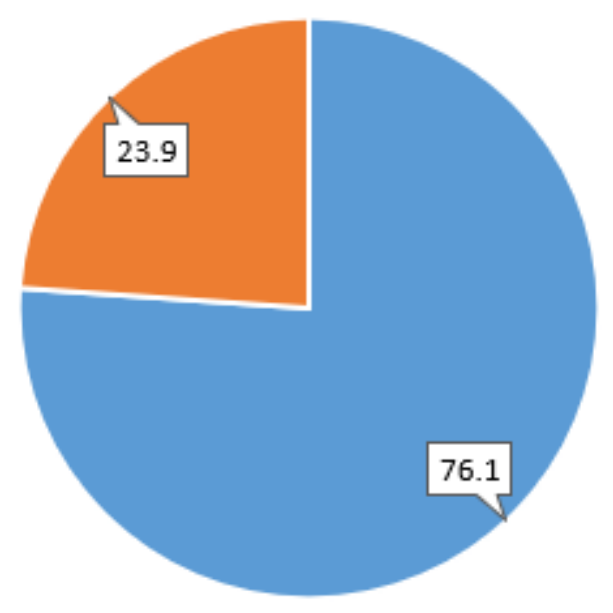

\section{Figure 2}

Male involvement in birth preparedness and complication readiness during the last pregnancy in West Arsi Zone, 2019.

\section{Supplementary Files}

This is a list of supplementary files associated with this preprint. Click to download. 
- STROBEMALEINVOLVEMENT.docx 